\title{
Scalable Technology to Produce Pharmaceutical Grade Plasmid DNA for Gene Therapy
}

\author{
Odalys Ruiz Hernández, Miladys Limonta Fernández, Jorge Valdes \\ Hernández, Martha Pupo Peña and Eduardo Martínez Díaz \\ Center for Genetic Engineering and Biotechnology \\ Cuba
}

\section{Introduction}

The use of gene therapy is a promising process for the prevention, treatment and cure of diseases such as cancer and acquired inmudeficiency syndrome (AIDS); increasing a considerable interest during the last decade (Prather et al., 2003). This process requires considerable amounts of plasmid DNA (pDNA) that should be homogeneous with respect to structural form and DNA sequence (O’Kennedy et al., 2003).

It was shown that naked DNA injected into muscle tissue is expressed in vivo; also the introduction of immunogenic sequences can result in animal vaccination against the encoded peptide (Vogel \& Sarver 1995). In general, DNA-based vaccines are considered very safe due, in part, to the lack of genetic integration, and to the absence of specific immune response to the plasmid itself (Robinson, 2000), making its property very attractive. This approach was successfully tested for vaccination against several viral infections such as: West Nile virus vaccine licensed in 2005 by the USDA; in horses; is currently in phase II trial in humans; and the H5N1 influenza DNA vaccine currently undergoing phase I clinical trials (Phue, 2008).

When the concept of a DNA vaccine first popped onto the scene in the early 1990s, it seemed too simple, too easy and too bizarre to be true. Regardless the considerable scientific effort over the past few years, no gene-therapy product has yet reached the market, at the moment. Only several clinical trials have been carried out and thousands of people have received (pDNA) without serious adverse effects (Prazeres et al., 1999). By virtue of the developments made recently in biotechnology and molecular medicine, the speculation of 20 years ago that gene technology would become a powerful tool to cure disease directly, has become reality (Schleef, 1999) and the market of one of these products would exceed US\$45 billion.

The trend toward testing DNA vaccines as part of combination trials can be seen in both the large vaccine producers like Merck, Aventis Pasteur and Wyeth as well as in smaller research companies (Powell, 2004). Although the processes of production for many genetherapy vectors have been developed in pharmaceutical companies, the information of large-scale pDNA production is scarce and usually not available to the scientific community (Xu et al., 2005). 
FDA added "Therapeutic plasmid DNA vector" to the list of well-characterized biotechnology product and gene therapy has been moved rapidly from laboratory scale to clinical trials. As a matter of urgency, it is essential to develop new protocols to obtain highquality plasmids with high yields. The understanding, optimization and validation of steps, from pDNA design and host strain selection to mass-cultivation and purification, are crucial if this novel vaccine technology will become commercially successful (Prather et al., 2003). Innovative methodologies and new engineering tools are needed to expand the window of opportunity for process design. The advantages of the procedure described over existing technology to produce pharmaceutical grade pDNA for gene therapy include a high cell density culture, improved plasmid purity and the elimination of undesirable process additives such as toxic organic extractants and animal derived components or raw materials. By employing this simple, scalable and applicable approach we concluded successfully clinical trial (phase I); and currently is in Phase II using the pIDKE2 plasmid; which is the main component CIGB's candidate vaccine against Hepatitis $\mathrm{C}$ virus. The principal topics of this chapter are: Fermentation process including design of high-cell-density culture, Downstream process using tangential flow filtration and chromatography, which are widely accepted methods for pDNA purification and act as orthogonal techniques platform, Scaleup of bioprocess, Quality control of pDNA manufacturing and finally regulatory aspects.

\section{Fermentation process to produce plasmid DNA}

For the production of large quantities of pDNA an efficient fermentation process needs to be established. The fermentation conditions for optimization of pDNA production in Escherichia coli (E. coli) could be fundamental however experimental data are limited. Although the available information is limited in comparison with the extensive recombinant protein production literature, some general rules and methodologies pertaining to the production of pDNA by cultivation of E. coli are beginning to emerge (Prather et al., 2003).

A number of recent reports discuss the fermentation strategies used for production of pDNA, but have not addressed the effect of fermentation conditions on the quality of the resulting pDNA. Few studies have been carried out focusing on the quality of plasmid product at the end of the fermentation stage. Because the location of pDNA is intracellular, productivity is proportional to the final cell-density and the specific productivity (amount of pDNA per unit cell mass) too (Yakhchali et al, 2007). Typically, $0.5-1 \mathrm{~g}$ pDNA per $\mathrm{Kg}$ of wet weight biomass is obtained from cultivation media using high copy number plasmid. Therefore the choice of fermentation protocol will be critical in minimizing process contaminants that need to be removed during downstream processing ( $\mathrm{O}^{\prime}$ Kennedy et al., 2003).

Generally, these simple processes are based on the growth of E. coli in either shake flasks or small laboratory fermentors, usually employing simple media formulation such as Luria Bertani (LB) or Terrific Broth (TB). These processes yield low cell mass, which support modest volumetric plasmid yields that are only sufficient for studies employing limited number of small animals (Prather et al., 2003).

Strategies aimed at increasing plasmid amplification in fermentation include the use of temperature shock, while achievable on a small scale, may be difficult to implement on a large scale. The use of fermentation devices is necessary too, so over the whole propagation of growth at least the following parameters are monitored and documented: temperature, $\mathrm{pH}, \mathrm{pO} 2$, agitation speed, and the use of some solution like: antifoam, acid, base and in some cases feeding solution. 
On the other hand the use of low specific growth rates $(\mu)$ is unifying principle in highquality, high-yield fermentations for pDNA production. Chen et al. 1997 indicated that the pDNA yield is related to the specific growth rate of bacteria during the fermentation. In addition, other authors suggest that the plasmid yields obtained from culture were highest into stationary phase. High specific growth rates are associated with acetate production, plasmid instability and lower percentages of supercoiled plasmid overall (Xu et al., 2005).

The FDA recognizes that open-circle, linear and nicked forms may be fewer effectives therapeutically than supercoiled DNA. Those other forms can be very difficult to separate from the supercoiled plasmid during purification. Therefore, fermentation processes should also be optimized to produce a high percentage of supercoiled plasmid (Carnes, 2005). Large scale E. coli fermentation systems for plasmid DNA production have been developed and the success of this process will be dependent on the interactions between the host organism, the recombinant plasmid vector, its copy number, the gene size and the growth environment.

\subsection{Host strain}

The first consideration in designing an efficient process should be host cell line selection. Host selection requires that the source of the microbial strain must be characterized and free of any adventitious agents, as well as be genotypically and phenotypically well characterized (Prather et al., 2003). Plasmids represent less than $0.5 \%$ of the wet biomass and endotoxins and other impurities must be completely removed so the characteristics of the microbial host affect the quality of the purified DNA.

Plasmid production should be in an E. coli K12 strain considered non-pathogenic. E. coli is usually chosen today as the production host, with its concomitant benefits and drawbacks. The benefits include a high DNA yield and well-established procedures for down-stream processing of the plasmid. However, as a gram-negative bacterium contains highly immunogenic endotoxin or lipopolysaccharides (LPS) in its outer membrane (Glenting, et al, 2005). Popular hosts such as DH5 derivates and XL1 Blue are suitable for plasmid production. Judicious selection of the host strain is also important because this can be minimize the amounts of impurities that needs to be removed by, for example avoiding strains that produce large amounts of carbohydrate such as HB101 (Prazeres et al., 1999). In our experience DH10B have been found to be consistently higher producing pDNA.

\subsection{Culture medium}

Medium composition and cultivation conditions play an important role by controlling amount of biomass, plasmid copy number and stability. It was reported that the media composition affected cell specific growth rate, and thus influenced in plasmid copy number. Therefore, the effects of medium components on cell growth and plasmid productivity should be evaluated (Xu et al., 2005).

Media composition can dramatically affect yield and consequently the overall cost of production. Media for plasmid production should support high nucleotide pools in cells and supply energy for replication while minimize other cell activity (Carnes, 2005). Through the type and concentration of ingredients used, cultivation medium composition directly dictates the amounts of biomass produced; is therefore likely to influence plasmid volumetric yield (Prather et al., 2003).

Typically, the nutritional requirements are satisfied by either minimal or complex media. The first option contains known quantities of essential nutritional components including 
carbon source, nitrogen source and salts and excludes components known to be inhibitory to bacterial growth. Complex media formulations often contain ingredients like yeast extract and peptones that may allow for a higher cell density. Fermentation processes using minimal media are highly reproducible and support higher plasmid copy number (Carnes, 2005). Although standard media can be used for plasmid production, some authors recommend the development of media adapted to the specific plasmid-host system involved in order to increase productivity (Prazeres et al., 1999). Media that supported similar specific growth rates between plasmid-bearing and plasmid-free cells also supported high plasmid stability.

Design of balanced medium is based on bacterial energy requirements and elemental composition (Carnes, 2005). A carbon source provides energy and biomass and is usually the limiting nutrient in fed-batch culture. Glucose is the conventional choice as a carbon source because it is inexpensive and very efficiently metabolized. However, high glucose levels have demonstrated to cause undesirable acetate production due to metabolic overflow. The application of glycerol avoids repression of intermediate metabolites and accumulations of inhibitive organic acids to some extent. Therefore, the effect of glycerol addition in culture and feed medium on pDNA production in E. coli should be also examined.

On the other hand the selection of nitrogen source and the determination of its concentration are critical to the optimization of plasmid production in recombinant cell fermentation. A nitrogen source and trace metals elements are required for bacterial growth, metabolism and enzymatic reactions. The bacterial requirement for nitrogen can be satisfied by inorganic and organic source. From the development of high density cell culture point of view, organic complex supply of nitrogen from components, such as yeast extract, is essential because it is more effective to support high plasmid yield. Minerals are necessary too for bacterial growth, metabolism and enzymatic reactions. For example it was reported that Magnesium sulphate is often the source of both magnesium and sulphur; and high concentrations are beneficial for the production of homogeneous supercoil plasmid monomers. Therefore, the effects of medium components on cell growth and plasmid productivity should be evaluated to solve the trade-off between higher copy number and reduced specific growth rate (Xu et al., 2005).

\subsection{High cell density culture}

A further feature of fermentation technology for large scale plasmid production is the performance of high-density culture to obtain large amounts of biomass. Fed-batch fermentation provides higher biomass yields than batch fermentation because substrate is supplied at such rate, that it is nearly completely consumed; so delivers nutrients over an extended period of time (Carnes, 2005). Both batch and fed-batch technologies have been successfully employed for plasmid over-production by E. coli. Batch cultivation, although logistically simple, is severely limited with respect to achieving elevated biomass (Prather et al., 2003).

Nutritional requirements and cellular composition of E. coli are well defined. This information that has been reported in literature can be advantageously used in the design of culture media formulation (Table 1) (Carnes, 2005). High cell density (HCD) fermentation requires a balanced medium supplying adequate amounts of nutrients needed for energy, biomass and cell maintenance; and commonly contains carbon and nitrogen sources, various 
salts and trace metals. HCD process has many inherent advantages, specifically reduces the time required in a fermenter in either a contract manufacturing facility or in captive space.

\begin{tabular}{ll}
\hline Element & Dry Weight Percentage \\
\hline Carbon & $50-53$ \\
Hydrogen & 7 \\
Nitrogen & $12-15$ \\
Phosphorous & $2-3$ \\
Sulfur & $0.2-1.0$ \\
Potassium & $1.0-4.5$ \\
Sodium & $0.5-1.0$ \\
Calcium & $0.01-1.10$ \\
Magnesium & $0.1-0.5$ \\
Chloride & 0.5 \\
Iron & $0.02-0.2$ \\
\hline
\end{tabular}

Table 1. Elemental component of bacteria.

In fed-batch fermentation cells are inoculated into an initial volume of medium that contains all nonlimiting nutrients and an initial concentration of the limiting substrate. These processes start with a batch phase, namely phase of biomass build up where the cells grow exponentially (Carnes, 2005) follow by a phase of slow growth, achieved via fed-batch technology, where plasmid amplification takes place. Several researches have observed that plasmid copy number increases during both, the late exponential and early stationary phases of growth (Prather et al., 2003). These kinds of cultivations lead to significantly higher biomass yields avoiding the loss of product. The amount of product per cell (or per cell weight) in particular strongly influences the downstream processing scale and therefore, defines another important part of the production costs (Schleef, 1999).

Several feeding strategies have been developed, either automated feedback controlled (e.g., DO-stat, $\mathrm{pH}$-stat, metabolic activity, biomass concentration and substrate concentration) or predetermined (e.g., constant, linear stepwise or exponential feeding). The feeding of nutrients, usually glucose, has been extensively researched and incorporates a range of approaches that span from simple to much elaborated, with each presenting its own advantages and disadvantages. One of the most effective feeding strategies is exponential feeding. This method allows a culture to grow at a predetermined specific rate $<\mu_{\max }$ without the need of feedback control. Feeding regimens based on feed rate increase, either simple or following sophisticated algorithms aimed at maintaining a more constant environment thus have been successfully implemented maintaining a desired growth rate (Prather et al., 2003).

However, HCD technique has its draw backs and growth inhibitory by products, such as acetate formed. Acetate formation can be reduced or prevent by altering the fermentation medium or optimization of feeding strategies during fed-batch fermentation. According to our literature survey, the effect of acetate on pDNA production in HCD culture has been little investigated (Yakhchali et al, 2007). It has been reported that a minimum acetic acid accumulation and a high plasmid copy number could be obtained when the specific growth rate is about $0.1 \mathrm{~h}^{-1}$. 
Using all this approach, we designed a fed-batch culture medium according to bacterial element composition to obtain the recombinant host $E$. coli DH10B bearing pIDKE2. This plasmid is the first 650 aa of the Hepatitis C Viral (HCV) polyproteins for DNA immunization expression from the $1 b$-Cuban isolate genotype (Dueñas et al., 2007). The results show that cell density increased during exponential phase at around 20-21 hrs, to the stationary phase at around 22- $25 \mathrm{hrs}$, and cell density decreased at $26 \mathrm{hrs}$. The highest cell mass $\left(29 \pm 1.7 \mathrm{~g}^{\text {dry cell }} \mathrm{l}^{-1}\right)$, plasmid yield $\left(154 \pm 2.8 \mathrm{mg}^{\mathrm{pDNA}} \mathrm{l}^{-1}\right)$ and specific pDNA yield $(0.44 \pm 0.02 \mathrm{mg}$ pDNA g-1 dry cell weight) were obtained at 24 hours of culture. So we suggest stop the culture in this moment (Ruiz et al, 2009).

The behaviour of E. coli (DH10B) in this fed-batch fermentation process (red bar in Figure 1) was common because the average of volumetric yield (154 $\left.2.8 \mathrm{mg}^{\mathrm{pDNA} \mathrm{l}} \mathrm{l}^{-1}\right)$ is in the state

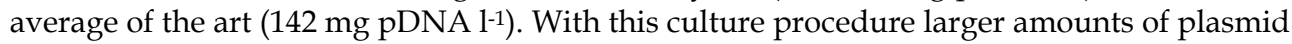
pIDKE2 can be obtained in DH10B cells. Several researchers have reported the behaviour of plasmid volumetric yield (mg/L) for different fermentation strategy (Figure 1) (Diogo, 2000, 2001; Durland, 1999; Lahijani, 1996; Shmidt, 2001, 2003; Wang, 2001). As it is shown, plasmid production under non optimized laboratory conditions invariably leads to very low volumetric titters $(5-70 \mathrm{mg} / \mathrm{L})$ and DNA production processes that employ simple batch cultivation technology yield relatively low biomass and correlatively support low plasmid volumetric yields too $(<100 \mathrm{mg} / \mathrm{L})$. However, increasing medium strength, by either adding additional nutrients, employing richer formulation or sophisticated feeding strategy (orange bar), support higher volumetric yield without compromising plasmid quality.

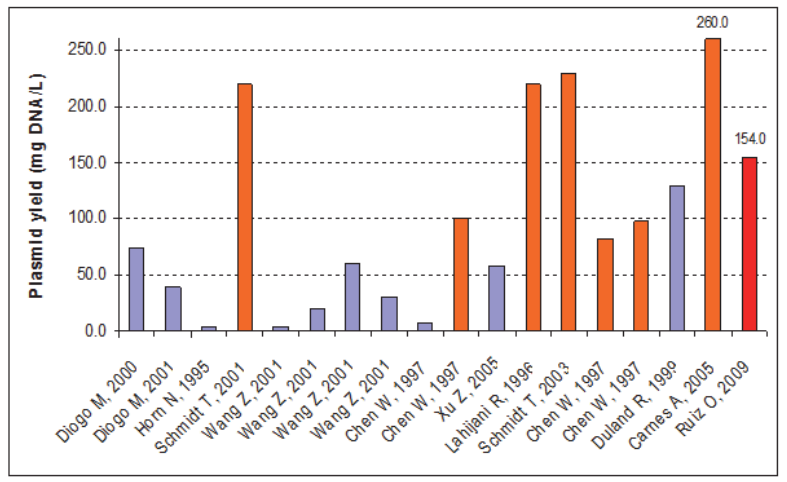

\begin{tabular}{ll}
\hline Culture Strategy & Reference \\
\hline Shake flask 2L (LB medium) & Diogo M, 2000 \\
Batch (TB medium) & Diogo M, 2001 \\
Batch (TBKmedium) & Horn N, 1995 \\
Fed Batch (exponential feeding) & Schmidt T, 2001 \\
Batch (LB medium) & Wang Z, 2001 \\
Batch (LB medium +Glucose) & Wang Z, 2001 \\
Batch (Defined media 1) & Wang Z, 2001 \\
Batch (Defined media 2) & Wang Z, 2001 \\
Fed Batch (manual feeding) & Chen W, 1997 \\
Fed Batch (DO-stat) & Chen W, 1997 \\
Shake flask (Defined media) & Xu Z, 2005 \\
Fed Batch (Temperature shock) & Lahijani R, 1996 \\
Fed Batch (DO-stat) & Schmidt T, 2003 \\
Fed Batch (DO-stat) & Chen W, 1997 \\
Fed Batch (pH-stat) & Chen W, 1997 \\
Batch (Defined media) & Duland R, 1999 \\
Fed Batch (Exponential feeding) & Carnes A, 2005 \\
Fed Batch (Constant feeding) & Ruiz O, 2009 \\
&
\end{tabular}

Fig. 1. Plasmid volumetric yields, from several references with different fermentation strategies.

A combination of plasmid and host-strain selection with optimization of fed-batch fermentation can result in yields as high as $260 \mathrm{mg} / \mathrm{L}$ (Carnes, 2005). Therefore HCD fermentation techniques for culturing $E$. coli has been developed to improve productivity and to obtain high cell density.

\subsection{Scale up}

When a molecular biologist thinks of a "large scale" pDNA production, the range of 10$100 \mathrm{mg}$ of DNA usually comes to mind. However, at a pharmaceutical production-scale, pDNA requirements may exceed $50 \mathrm{~g}$ per batch. In extreme case, many kilograms of pDNA 
per year will be needed to fill the ultimate marketing demand for DNA vaccines currently in clinical trials (Prather et al., 2003). The transfer from research scale technology to manufacturing scale requires management of the upscaling process. Such upscaling is not just a simple multiplication of relevant factors, but instead requires highest competence, time investment and incurs cost.

Effective scale-up is essential for successful bioprocessing. Much fermentation processes were successfully scale-up on the basis of a constant volumetric oxygen transfer coefficient (KLa) and power consumption per unit volume (P/V); so they are widely used. However when a particular scale-up strategy is carried out maintaining a specific set of parameters constant, other parameters can not be controlled and may change substantially in unexpected ways (Schleef, 1999).

Current scale-up methods assume that the environment conditions are homogeneously distributed within the large-scale fermentation, as in the small-scale fermentor, however, this is not true. There are so many factors, like hydrodynamics factors, height and geometric configuration of the reactor that would affect the environment of the fluid in the large-scale reactors. The use of traditional empirical methods lead to an increase in mixing and circulation times at large scale. In addition high oxygen demands and high viscosity can cause concentration gradients in oxygen, shear and $\mathrm{pH}$; that can have a significant impact on fermentation yield. Therefore, the choice of scale-up criteria in not an easy task, given the potential sensitive and diverse response of cells to each of the transport phenomena influenced by impeller design, system geometry, scale, fluid properties, and operating parameters.

The primary scale-up criterion of process should be selected based upon the transport property most critical to the performance of the process. If oxygen transfer is the limiting factor, then scale up by equal $\mathrm{P} / \mathrm{V}$ will be essential. This method is adopted for many authors using larger-scale fermentors, such as these below 1000L capacity (Pollard et al., 2007). Moreover, the suitability of scaled-up methods is usually confirmed by experimental results. Scale-up of plasmid pIDKE2 production from 5L fermentor to 50L pilot scale fermentor was carried out successfully using constant $\mathrm{P} / \mathrm{V}$ in a fed batch process illustrated in epigraph 2.3. Final biomass concentration and specific pDNA yield were increased in comparison with cultures grown on a standard laboratory medium (TB) on batch mode as we can see in Figure 2.

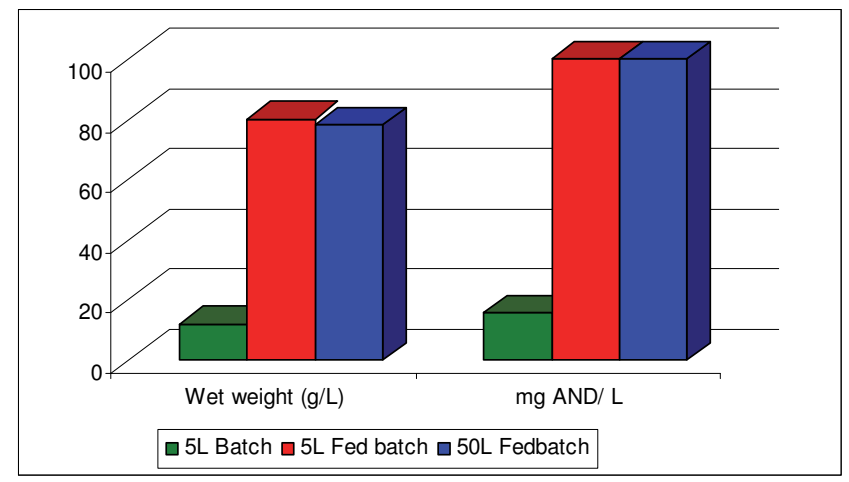

Fig. 2. Effects of culture strategy and scale on pDNA production and cell growth. 
The results show that there is no difference in fermentation between small and large bioreactors carried out in fed-batch condition. Besides in both cases the cell growth and volumetric plasmid yield were higher than batch production (Figure 2). So this fermentation process is very easy to scale up and has been used to provide plasmid yield that are becoming acceptable from a manufacturing viewpoint. The productivity of this process is much higher than the previous works which may be suitable for large scale production of DNA vaccine.

\section{Downstream process}

Low concentrations of pDNA ( 0 - 3\% dry weight) depending on size and number of plasmid copies in cells of $E$. coli involve an economic challenge in the development of an efficient technology for the production of large quantities of plasmids DNA (pDNA) for therapeutic purposes. The pDNA are macromolecules with hydrodynamic diameter between $150-600$ nm depending on the molar mass which can be between 3 to $200 \mathrm{MDa}$; while the chromosomal DNA (cDNA) has a molar mass of $2700 \mathrm{MDa}$, having similar properties. So, it becomes difficult to separate from pDNA.

There are reports that describe two basic stages: the first one includes the construction and appropriate expression vector, and the choice of host strain, followed by selection and optimization of fermentation conditions. The second one is related with the plasmid isolation and subsequent steps for purification. The purification strategy properly selects and integrates the operation steps; at the beginning carries out cell disruption and after that the clarification and concentration, with the aim to eliminate impurities and cellular debris; simultaneously develop concentration and preparation for further purification of the plasmid. The second step is designed using chromatographic media thus separate pDNA of impurities related to the structure, such as linear and open circular plasmid, chromosomal DNA, RNA, endotoxins and proteins remaining (Limonta et al., 2008).

\subsection{Cell disruption by alkaline lysis}

The rupture of cells for the release of pDNA is the first and probably the most critical and problematic of all unit operations during the purification processes. The maximum amount of supercoiled plasmid should be obtained to ensure a high performance process. The chemical lysis of the cell was first reported by Birnboim and Doly (Birboim et al., 1979); achieved by breaking the cell wall and membrane with a buffer which contains sodium hydroxide and sodium dodecil sulphate detergent, then begins the release of intracellular products, subsequently is added potassium salt in order to get, as precipitated, cell debris and proteins. The cell disruptions protocols vary taking into account the salt concentration, the sample volume, $\mathrm{pH}$, temperature and time of each step individually.

Several factors may influence the release of plasmid. These include the number of copies of the vector, the host cell, growing conditions and environment. It is valid to note that the duration of this step can affect the yield and purity of the final product. Levy and colleagues (Levy et al., 1999) found that laminar flows were required to break the plasmid and according to their size would take a longer or shorter time the rupture of the cell.

In the alkaline environment the molar mass of cromosomal DNA is denatured, while in a $\mathrm{pH}$ range of 12.0 to 12.5 the pDNA double chain remains intact. This $\mathrm{pH}$ range is considered appropriate. If the $\mathrm{pH}$ of the medium is very low, the cDNA won't be completely denatured, and can cause subsequent purification affectations. On the other hand, high $\mathrm{pH}$ levels (higher than 13) cause effects on the structure of pDNA by denaturing irreversibly. 
The rupture of the cell occurs as the components are mixed, due to the solubilisation of the cell membrane in alkaline solution containing SDS. This process takes 20 to $40 \mathrm{~s}$ to complete, depending on the mixing conditions. Studies have shown that the amount recovered by cells used in the breaking step, depends significantly on the volume of solution used for the treatment of cells (Meacle et al., 2003).

The homogenization of the sample plays an important role, mixing should be accomplished with sufficient intensity to achieve an appropriate level of distribution of chemical reagents. The homogenization is difficult due to changes in the rheological properties of the solution. In the second stage of the rupture process known as neutralization, the $\mathrm{pH}$ of the mixture is reduced abruptly broken by the addition of potassium acetate. The change in the physicalchemical conditions of the cDNA causes flocculation and precipitation of a complex of proteins, SDS and other species of high molar mass and RNA. Achieve the optimization of the process of rupture is important for further recovered from pDNA that must be purified in the following stages.

\subsection{Plasmid recovery}

At the end of the break alkaline forming a precipitate containing cell debris, denatured proteins and nucleic acids, which must be eliminated, using a unit operation in solid-liquid separation, either by centrifugation, filtration or the combination of these operations with the precipitation. The centrifuge with fixed angle rotor operation is commonly used at laboratory scale. However, it is not suitable for large scale production of pDNA. Industrial centrifuges typically operate with a continuous power flow. The centrifugal acceleration of fluid shears and consequently causes the rupture of the material precipitated and the pDNA molecules.

Dead-end filtration is a convenient choice at large-scale operation in the production process of the plasmid. Over $67 \%$ of recovered with a purity of $46 \%$ of this total was obtained after cutting $99 \%$ of the precipitate formed at the end of the break alkaline with filter pore diameter of 5 microns (Prazeres et al., 2004). Another choice at large-scale operation is tangential flow filtration. Once the pellet is separated, the clarified alkaline lysate containing the plasmid can be concentrated removing the impurities. However, neither dead end filtration nor tangential flow filtration remove all the RNA without the uses of critical reagents such as animal-derived compounds (e.g., enzymes), or salts. The use of this unit operation would help to reduce the filtration pressure, in order to avoid precipitate shear and stripping of the chromosomal DNA fragments.

The use of precipitation for the purification of pDNA is reported with the use of natural and chemical precipitants such as calcium chloride salt, after the step of breaking made alkaline to achieve selective precipitation of the cDNA and RNA, obtained as a result, reduction of 50 to $70 \%$ of RNA and cDNA, respectively, and the loss of $10 \%$ of pDNA. There are also reports of use of other agents which leads to a reduction in volume by concentration and removal of nucleic acids of low molar mass using agents such as isopropanol, polyethylene glycol (PEG) or cetyl trimethylammonium bromide (CTAB) (Lander, 2002; Ribeiro, 2002). Precipitation with ethanol and isopropanol is favourable laboratory scale but not at large scale; it implies a high investment cost. However, the precipitation with the cationic detergent $C T A B$ provides good selectivity and elimination of the cDNA. The use of CTAB and PEG is considered advantageous option for precipitation, but in none of the cases cited by $100 \%$ eliminates RNA. 
Ultrafiltration and microfiltration are also considered as an option in the first steps of purification. The use of tangential flow ultrafiltration polyethersulfone membrane pore diameter between 100 and $500 \mathrm{kDa}$, can eliminate $70 \%$ of RNA and $90 \%$ protein (Butler, 2001). Bussey reported the use of tangential flow ultrafiltration for purification of pDNA (Bussey, 1998). He proposes the use of membranes with a pore diameter between 300-500 $\mathrm{kDa}$, the $500 \mathrm{kDa}$ membranes were used for plasmids ranges between $15-50 \mathrm{~kb}$.

The liquid - liquid extraction is another operation that can be used also for the intermediate step of purification using the aqueous two-phase systems (ATPS). So far they have been reported for the purification of pDNA, two-phase systems formed by PEG and salt polymer K2HPO4 (Ribeiro, 2002), where yields are reported 39, 42 and 100\% molar mass PEG 300, 600 or 1000 respectively. The two-phase aqueous systems are easily scaled without a noticeable change in the nature and process efficiency, enabling high yields, a continuous process and reducing operational costs in relation to the costs of other conventional operations. These systems are very useful in the biotechnology industry as $\mathrm{K}_{2} \mathrm{HPO}_{4}$ salt is very cheap compared to other polymers such as dextran.

Biopharmaceuticals produced from pDNA purity levels required for this component over $90 \%$ and is usually achieved by the inclusion in the purification step by the combination of two or three chromatographic processes. The main objective is to separate the pDNA of impurities (in terms of composition and structure). Chromatographic operations described in the literature for the purification of plasmids include properties such as: plasmid size, charge, hydrophobicity, conformation and accessibility to a specific molecular group. Among the most common techniques for obtaining pDNA are: ion exchange chromatography (IEX), the hydrophobic interaction chromatography (HIC), affinity chromatography and exclusion chromatography molecular mass (SEC) (Stadler et al., 2004).

\subsection{Purification process development for plasmid DNA gene therapy}

Historically, highly purified pDNA recovery is accomplished through the use of cesium chloride / ethidium bromide ( $\mathrm{CsCL} / \mathrm{EtBr})$ buoyant density gradient separation. This method allows the separation of pDNA by buoyant density into purified bands of different forms: supercoiled plasmid (sc), open circular (oc), linear (l) and multimeric (m). While it yields highly purified plasmid, this approach is not scalable because of personnel safety issues and the hazardous waste considerations associated with the use of cesium chloride and ethidium bromide. In addition the use of ultracentrifugation is also a major impediment to the scale up of this technology.

On the other hand, simple unit operations and the avoidance of critical reagents such as animal-derived compounds (e.g., enzymes), detergents and organic solvents significantly reduce the effort for validation and for precautions regarding patient and operator safety. The employment of these process solutions at large scales requires safety measures such as the design of explosion-proof facilities or use of appropriate protection. It is strictly recommended to spend sufficient time and efforts in upscale-related process development according to GMP. This may end up in a different approach when compared with ' $k i t^{\prime}$ protocols in which convenience and simple robustness play the most important role. Depending on the final application as a therapeutic (single-shot high-dose, or long-term low-dose treatment) or for diagnostics, the specific demands may require individual solutions. Given the complexity of the starting material, certainly any single purification step will not be enough to fulfil the demands of the regulatory authorities. Nevertheless, the 
aim is to end up with a robust and preferably generic protocol, which is applicable to a variety of plasmids of different sizes (regardless of individual precautions related to stability and sensitivity to shear forces). When developing a multi-step large-scale pDNA Purification process, the design will aim to begin with fast volume reduction. This can be achieved by ultrafiltration or any (chromatographic) capture step, in which recovery $(>90 \%)$ is more important than maximal capacity.

Currently published processes for pDNA purification include precipitation and extraction of pDNA by organic solvents, ultrafiltration, and predominantly liquid chromatographic techniques which are the most widely used for this purpose. Most of the available processes for pDNA purification are time-consuming and not scalable. Furthermore, due to the application of materials that are not certified for application in humans or due to the application of enzymes of avian or bovine origin and of toxic reagents such as phenol, $\mathrm{CsCl}$, $\mathrm{CsBr}$, etc., these processes do not meet the appropriate guidelines of the regulatory authorities.

Our pDNA purification process is based on alkaline lysis, tangential flow filtration and size exclusion chromatography for extensive removal of RNA as primary downstream steps. Chromatography is considered as the method with highest resolution, therefore being essential for producing pDNA suited for therapeutic applications. It has to be considered that the large pDNA molecules adsorb only at the outer surface of particulate supports. Consequently capacities are usually on the order of hundreds of micrograms of plasmid per millilitre of chromatographic support (Limonta et al., 2010). We used a reverse phase POROS R1 50 matrix which has a dynamic binding capacity between 5 and $1.5 \mathrm{mg}$ pDNA per $\mathrm{mL}$ support this matrix is used to purify the pDNA from the remaining impurities, particularly due to its ability to reduce the endotoxin burden to levels below the specifications. Volume reduction of the resulting stream is achieved by tangential flow filtration prior to the final size exclusion chromatography which is used as a polishing step to remove the undesired pDNA isoforms, host proteins and to exchange the buffer for an adequate formulation.

The proposed process reach a $95 \%$ of pDNA, the final genomic DNA content is lower than 5 ng per dose, RNA is not detectable by agarose gel electrophoresis, and protein content is lower than $5 \mu \mathrm{g}$ per dose and the endotoxin content $0.6 \mathrm{EU}$ per $\mathrm{kg}$ body weight. The results demonstrate that process fulfil all regulatory requirements and delivers a pharmaceutical grade pDNA This process does not use or generates significant amounts hazardous materials and no special safety requirements are envisaged. Thus, environmental or safety associated costs are kept to minimum. The reagents used do not pose any special regulatory concern since they are non toxic, non mutagenic and non flammable.

\section{Quality control}

\subsection{Overview}

In the US therapeutic gene products are regulated by the FDA Centre for Biologics Evaluation and Research (CBER). In Europe this task is performed by the European Agency for Evaluation of Medical Products (EMEA). The recommendations made by these and others international agencies provide specific quality-control and safety criteria for each therapeutic gene product, reflecting the intended use of the product compliance with Good Laboratory Practice (GLP) and current Good Manufacturing Practice (cGMP). A guiding principle for production of biological products implies to build quality into the product 
during the process but not to test quality. That is why, it is important to develop appropriated and validated analytical methods for all phases of a GMP process. Quality testings have to be applied since the very beginning to raw material and further established in process and for the purified bulk plasmid. They all must comply with acceptance criteria, regarding identity, purity, potency and safety of the final product.

\subsection{MCB and WCB}

The Master Cell Bank (MCB) and Working Cell Bank (WCB) are required to ensure each manufacturing run. Quality control methods must be developed to confirm the identity and stability of bacterial host cell and pDNA contained in a MCB and WCB used for the production of pDNA. Cell bank should also be analyzed for cell viability, plasmid copy number, the presence of plasmid-free cells, adventitious agent and viral contaminations. Identity test for pDNA should include analysis of diagnostic restriction enzyme digestion patterns and the full DNA sequence of plasmid. These analyses are typically performed using pDNA isolated from cultures derives from the WCB. Restriction enzyme analysis typically involves digestion of the plasmid with a predefined set of restriction enzymes followed by analysis by an agarose gel electrophoresis analysis and staining with ethidium bromide.

\subsection{Control of production process}

Likewise for viral vectors the raw materials used in the production process should be characterized. Furthermore, the production process should be controlled by in-process controls. For plasmid vectors these include the control of the amount of plasmid prior to culture harvesting, the amount and form of plasmid after extraction step and the absence of endotoxins in the plasmid pool after extraction step. Specific regulations have been established to provide guidance in the use of vectors in clinical trials for the application and marketing authorization in the production and quality control. Regulatory guidance is given to the environmental protection areas of the patient and not to environmental protein in Europe and in the USA that include: Regulation in Europe, in the Netherlands, in the USA, Good Manufacturing Practice facilities and guidelines that have been established respectively by the Committee for Proprietary Medical Product (CPMP) of the EMEA and CBER of the FDA for the production and control of gene therapeutics and DNA vaccines.

\subsubsection{In-process controls}

In-process control is required that methods be developed to assay product yield and purity at critical step in the manufacturing process. Bacterial contaminates such as genomic DNA, RNA, protein and endotoxin should be monitored. The amount and purity of plasmid should be controlled prior to culture harvesting and purification steps. The control of the mass of plasmid into the cells prior to culture harvesting is especially important. The monitoring of the pDNA fermentation processes is a key issue in process development, validation and for product approval. Therefore, the reliable analytical methods for the quantification of pDNA from an impure plasmid solution are especially important.

We established a method in which is use the conventional agarose gel electrophoresis for quantification of pDNA pIDKE2. This method consisted in the application of pDNA (pIDKE2) on the range from 113 to $900 \mathrm{ng}$ and defined volumes of the three replicas of the pDNA isolated from $10 \mathrm{mg}$ of bacterial cell pellet by alkaline-treatment procedure assay. 
The electronic photograph of the gel is analyzed by image analysis software (software 1DManager ver. 2.0) and the plasmid isoform peaks areas for each line were summed (Total Area plasmid). The linear regression between the plasmid mass and the total area plasmid for calibration curve were determined and plasmid mass in each replica was estimated by using the standard calibration curve and taking account the applied volume of the sample. Mean plasmid mass on the sample (between three replicas) was determined with a variation coefficient that should not be superior to $15 \%$.

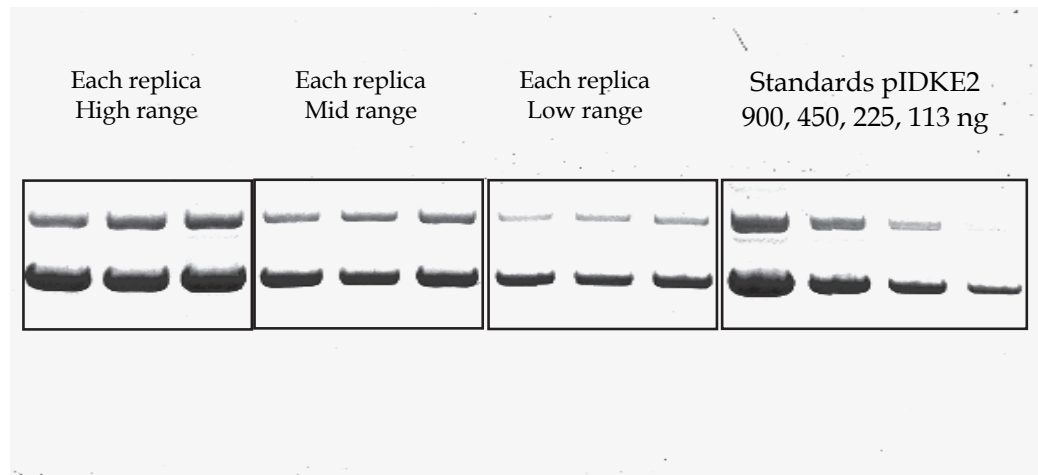

Fig. 3. Electrophoresis agarose gel. Three replicas of sample in the high (lines 1-3), mid (lines 4-6) and low (lines 7-9) range and calibration curve 900, 450, 225 and 113 ng (lines 10-13).

The validation of this method showed that independently of the fact that the applied mass of plasmid is in high, mid and low range, the plasmid mass determinate in the sample were similar (variation coefficient should not be superior to $15 \%$ ). A lineal relationship between plasmid amounts versus total plasmid areas was obtained. Three different assays with three replicas of the pDNA standards pIDKE2 calibration curve were run obtaining a determination coefficient $(\mathrm{R} 2)$ greater than 0.98 ( $\mathrm{P} \leq 0.01$ in ANOVA regression and $\mathrm{P} \geq 0.05$ in ANOVA lack off fit).

Figure 3 shown one assay, this analytical method proved to be specific, linear, precise and accurate in the interval of studied amounts. For the approval of one lot of Wet Biomass, the relation should be more than $0.6 \mathrm{mg}$ of pDNA/gram of Wet Biomass.

\subsubsection{Pure bulk plasmid}

Quality control testing of pure bulk plasmid must be capable of determining plasmid identity, purity, sterility, potency and safety. Guidelines by the $\mathrm{ICH}$ ensure that all tests and analytical protocols should be validated in terms of accuracy, specificity, detection limit, quantification limits, linearity and precision. Guidelines are provided by regulatory agencies for product characterization and in-process controls. Furthermore, analytical methods and product specifications for pDNA are described exhaustively in literature (Horn et al., 1995; Middaugh et al., 1998; Schorr et al., 1995).

In general, identification of a plasmid can be performed by size, sequence or expressed gene of the plasmid. The size can be performed by restriction enzyme mapping. The restriction fragments can be separated by agarose gel electrophoresis, capillary electrophoresis or HPLC. Capillary electrophoretic separation of restriction fragments is superior to gel 
separation in resolving power, analysis time and quantification (Weiss et al., 1995). The sequence can be performed by sequencing the whole plasmid. Its insert can be performed by automates sequencing method and can be used to check the identity of the plasmid. Chip technology is a promising new technology that allows a confirmation of a sequence of several kilobases. The currently available sequencing methods cannot identify small quantities of a mutated site $(<10 \%)$ present in a plasmid preparation (Maschke et al., 1993) In the final product could be present process-related impurities (genomic DNA, RNA, host proteins and endotoxins) and product-related impurities (open circular (oc), linear DNA isoforms, denatured and multimeric forms) that should be controlled. Contamination of biologics with genomic DNA has always been a mayor Quality Assurance concern due to the possibility of insertional mutagenesis into the recipient genome. Regulatory standards will require level of host cell genomic DNA below $10 \mu \mathrm{g} / \mathrm{mg}$ pDNA (Horn et al., 1995). The host cell DNA contamination can be quantified by Southern blot techniques with a probe specific for host cell gDNA (Levy et al., 2000a), application of the polymerase chain reaction (PCR), real-time PCR (Lahijani et al., 1998; Smith et al., 1999) that assess very low levels of gDNA in the final product. Another technique is agarose-gel electrophoresis, in which gDNA levels should be undetectable. The level of RNA is kept below or undetectable on a $0.8 \%$ agarose gel or by analytical anion-exchange chromatography (Horn et al., 1995). The content of proteins in final plasmid preparations is kept below $10 \mathrm{ng} /$ dose (Sofer \& Hagel, 1997); it should be undetectable by bicinchoninic acid (BCA) assay or silver-stained gel.

A specification should exist for the minimum amount of plasmid in the supercoiled form. Regulations may require $>80-90 \%$ of the plasmid to be in the supercoiled form. Homogeneity of the plasmid and the different isoforms of pDNA are determined by gel electrophoresis. The proportion of supecoiled and open circular pDNA can be quantified by densitometry scanning of an agarose-gel electrophoresis, capillary electrophoresis or chromatographic techniques.

Denatured supercoiled plasmid runs at the same speed as supercoiled plasmid in agarose gels. This form can be discriminated by HPLC using anion exchange chromatography. The denatured supercoiled plasmid elutes shortly after the main plasmid peak (Schluep et al., 1998). Another method that can be used is the fluorescence-based method SCFluo (Levy et al., 2000b), which is based on the reversible denaturation of sc DNA and the high specificity of the PicoGreen fluorochome for doble-stranded DNA.

It is known that the efficacy of binding of ethidium bromide to supercoiled DNA is different from the efficacy of binding ethidium bromide to closed circular, open circular or lineal DNA (Bauer \& Vinograd, 1968). Therefore, it's necessary to determine the relationship between fluorescence and relative band intensity for different configurations of DNA. The linear and open circular material fluoresced with equal intensity and the specific fluorescence of these species is $1.36 \pm 0.02$ time greater than that supercoiled DNA. A simple and rapid technique to quantify the proportion of supercoiled circular DNA is SCFluo (Levy et al., 2000a), which is a fluorimetric method that is based on the reversible denaturated of scDNA and the high specificity of the PicoGreen fluorochrome for double-stranted DNA.

Endotoxins (lipopolysaccharides) are mayor components of the outer cell wall of gramnegative bacteria and can copurify with the pDNA, which can cause side effects if administered to the recipient. They should be less than 0.1 endotoxin unit (EU)/ $\mu \mathrm{g}$ pDNA (Horn et al., 1995) and can be measured by gel-clot assay of aqueous extracts obtained from circulating Limulus polyphemus (horseshoe crab) amoebocytes lysate ('LAL assay'). DNAconcentration (dose) in the product can be measured by spectrophotometer analysis to 260 
$\mathrm{nm}$. This value is reliable if the $\mathrm{A}_{260} / \mathrm{A}_{280}$ ratio will be between 1.75 and 1.85, which means that the DNA product is free from the protein contamination.

\begin{tabular}{|l|l|l|}
\hline Test & Limits & pIDKE2 results \\
\hline Appearance & Clear, colorless solution & Clear, colorless solution \\
\hline Identity & $5541 \mathrm{pb}$ & $5541 \mathrm{pb}$ \\
\hline Restriction sites & Consistent with Map & Consistent with Map \\
\hline Biological Activity & $>25 \%$ seroconversion against \\
& Co.120 and E2.680 & $\begin{array}{l}26.6 \% \text { v Co.120 } \\
\text { and } 33.3 \% \text { vs E2.680 }\end{array}$ \\
\hline Sterility & $\begin{array}{l}\text { No growth-14 days } \\
\text { in rich media }\end{array}$ & $\begin{array}{l}\text { No growth-14 days } \\
\text { in rich media }\end{array}$ \\
\hline Endotoxin & $\leq 5$ EU / kg body weight & 0.6 EU/ kg body weight \\
\hline General Safety & absence of toxic effects & Pass the test \\
\hline Purity pDNA & $\geq 90 \%$ & $95 \%$ \\
\hline \hline RNA & $\begin{array}{l}\text { No visualized on } \\
0.8 \% \text { Agarose Gel }\end{array}$ & $\begin{array}{l}\text { No visualized on } \\
0.8 \% \text { Agarose Gel }\end{array}$ \\
\hline \hline pDNA concentration & $1.5-2.5$ mg/mL & $1.71 \mathrm{mg} / \mathrm{mL}$ \\
\hline \hline E. coli DNA & $\leq 5 \mathrm{ng} /$ dose & $\leq 5 \mathrm{ng} /$ dose \\
\hline \hline Host Protein & $\leq 5 \mu \mathrm{g} /$ dose & $1.4 \mu \mathrm{g} /$ dose \\
\hline pH & $6.7 \pm 0.2$ & 6.71 \\
\hline
\end{tabular}

Table 2. Testing results of release purified pIDKE2 compared to specification limits.

In the specific case of the production of pIDKE2 plasmid, analytical methods were followed according to the criteria recommended by the FDA. In table 2 is show a summary of the analytical specifications and final results (Limonta et al., 2008). Limits are according to the specifications of bacterial cell lysates and accepted levels of impurities for the final products described on the Guidance for industry "Considerations for pDNA Vaccines for infectious disease indications."

The results demonstrated that this process meets all regulatory requirements and delivers pharmaceutical grade pDNA. Vaccination with this plasmid (pIDKE2) in HCV chronicallyinfected individuals was safe, well tolerated and did not impair the ability to respond to non-HCV antigens (Castellanos et al., 2010).

\section{Acknowledgments}

I would like to thank Pérez, M.; Díaz, M.; Frometa, W.; Martínez, S., for technical support, as well as Márquez, I.; Hernández, S.; Varas, L.; Lugo, V; Bonilla, R. and Fernández, R. for help me with the work.

\section{Conclusions}

The large-scale plasmid production for gene therapy presents very specific problems as the reproducibility of process. Solutions for these problems and others will undoubtedly have an impact on the economics, efficacy and safety of non-viral approaches to gene therapy. As advances continue in the field of DNA vaccines, factories capable of producing kilograms of pDNA per year must be design. 
The choice of a manufacturing route is dictated by the balance between improvements in yield and purity of supercoiled pDNA achieved through the application of new technologies. The Biopharmaceutical industry is a highly regulated sector and to get into a regulatory approval for a new process or product is a major consideration. The recommendations made by some international agencies such as FDA and EMEA provide specific quality-control and safety criteria for each therapeutic gene product. The clinical application of gene therapy and DNA immunization will depend not only on efficacy but also on safety and the ease with which the technology may be adapted for large scale pharmaceutical production.

The advantages of the procedure described over the existing technology to produce pharmaceutical grade pDNA for gene therapy include a high cell density culture, improved plasmid purity and the elimination of undesirable process additives such as toxic organic extractants and animal derived enzymes. By employing this simple, scalable and applicable approach we concluded successfully a phase I clinical trial (Castellanos et al., 2010; Limonta et al., 2010) currently is in Phase II using the pIDKE2 plasmid; which is the principal component of a candidate vaccine against the Hepatitis $C$ virus.

\section{References}

Bauer, W. \& Vinograd, J. (1968). The interaction of closed circular DNA with intercalative dyes. J. Mol. Biol. Vol 33, pp. 141-171.

Birboim, H. \& Doly, J. (1979). A rapid alkaline extraction procedure for screening recombinant pDNA. Nucleic acid, Vol7, pp. 1513-1523.

Bussey, I. (1998). Methods for purifying nucleic acids. International Patent Aplication WO 98/05673.

Butler, E. (2001) Purification of pDNA, US Patent 6,313,285.

Carnes, A. (2005). Fermentation Design for the Manufacture of therapeutic pDNA. BioProcess International, pp. 2-7.

Castellanos, Z.; Dorta, Z.; Veliz, G.; Vega, H.; Lorenzo, I.; Ojeda, S.; Dueñas, S.; Alvarez, L.; Martínez, G.; Ferrer, E.; Limonta, M.; Linares, M.; Ruiz, O.; Acevedo, B.; Torres, D.; Márquez, G.; Herrera, L. \& Arús E. (2010). Immunization with a DNA vaccine candidate in chronic hepatitis $\mathrm{C}$ patients is safe, well tolerated and does not impair immune response induction after anti-hepatitis B vaccination. J Gene Med., Vol12, No. 1, pp.107-116.

Chen, W. (1999). Automated High Yield fermentation of pDNA in Escherichia coli. US Patent 5,955,323. American Home Products Corporation, Madison NJ.

Chen, W.; Graham, C. \& Ciccarelli, R. (1997). Automated fed-batch fermentation with feedback controls based on dissolved oxygen (DO) and $\mathrm{pH}$ for production of DNA vaccines. J Ind Microbiol Biotechnol, Vol18, pp.43-48.

Diogo, M.; Queiroz, J.; Monteiro, G.; Martins, S.; Ferreira, G. \& Prazeres, D. (2000). Purification of a cystic fibrosis plasmid vector for gene therapy using hydrophobic interaction chromatography. Biotechnol Bioeng, Vol68, No. 5, pp.576-83.

Diogo, M.; Ribeiro, S.; Queiroz, J.; Montiero, G.; Tordo, N. \& Perrin, P. (2001). Production, purification and analysis of an experimental DNA vaccine against rabies. J Gene Med, Vol3, pp.577-584.

Dueñas, S.; Alvarez, L.; Musacchio, A.; Acosta, N.; Falcón, V.; Martínez, G.; Amador, Y.; Guerra, I.; Alvarez, J.; Pérez, A.; Linares, M.; Limonta, M.; Ruiz, O.; Bacardí, D.; Viña, A.; Morales, J.; Torres, D.; Márquez, G.; Marante, J.; de la Rosa, M.; Vega, M.; Aguilar, J.; Soria, Y.; Pichardo, D.; Martínez, E.; Muzio, V.; Vázquez, M.; Acevedo, 
B.; Guillén, G.; Cosme, K.; Quintana, M.; López, P. \& Herrera, L. (2007). New alternatives for the development of vaccine preparations: contributions to the knowledge on the interaction of recombinant protein viral antigens with nucleic acids. Biotecnología Aplicada, Vol24, No. 3-4, pp. 311-314.

Durland, R. \& Eastman, E. (1998). Manufacturing and Quality Control of plasmid based gene expression systems. Adv Drug Deliver, Vol30, No. 1, pp. 33-48.

Glenting, J. \& Wessels, S. (2005). Ensuring safety of DNA vaccines. Microbial Cell Factories, Vol 4, No. 26, pp. 1-5.

Horn, N.; Meek, J.; Budahazi, G. \& Marquet, M. (1995). Cancer gene therapy using pDNA: purification of DNA for human clinical trials. Hum Gene Therapy, Vol6, pp.565-73.

Lahijani, R. (1996). High-Yield production of pBR322- derived plasmids intended for human gene therapy by employing a temperature controllable point mutation. Hum Gene therapy, Vol 7, No. 16, pp. 1971-1980.

Lahijani R, Duhon M, Lusby E, Betita H \& Marquet M. (1998). Quantization of host cell DNA contaminate in pharmaceutical-grade pDNA using competitive polymerase chain reaction and enzyme-linked immunosorbent assay. Hum Gene Ther, Vol9, No.8, pp.1173-1180.

Lander, R. (2002). Fractional precipitation of pDNA from lysate by CTAB. Biotechnol. Bioeng., Vol79, pp. 776-784.

Levy, M.; Ciccolini, S.; Yim, T.; Tsai, N. Titchener, P.; Shamlou, A. \& Dunnill, P. (1999). The effects of material properties and fluid flow intensity on pDNA recovering during cell lysis. Chem. Eng. Sci., Vol54, No.14, pp. 3171-3172.

Levy, M.; Collins, J.; Tsai. J.; Shamlou, P.; Ward, J. \& Dunnill P. (2000). Removal of contaminant nucleic acids by nitrocellulose filtration during pharmaceutical-grade pDNA processing. J Biotechnol, Vol 76, No 2-3, pp. 197-205.

Levy, M.; Lotfian, P.; O'Kennedy, R.; Lo-Yim, M. \& Shamlou, P. (2000). Quantitation of supercoiled circular content in pDNA solution using a fluorescence-based method. Nucleic Acids Res, Vol 28, No. 12, pp. E57.

Limonta, M.; Márquez, G.; Rey, I..; Pupo, M.; Ruiz, O.; Amador-Cañizares, Y. \& DueñasCarrera, S. (2008). PDNA Recovery using size-exclusion and perfusion Chromatography. BioPharmInternational, Vol21, No 9, pp. 38-47, ISSN 1542-166X.

Limonta, M.; Márquez, G.; Pupo, M. \& Ruiz, O. (2010). The Purification of pDNA for clinical trials using membrane chromatography. Bipharm International. Vol23, No.2, 46-54, ISSN 1542-166X.

Maschke, H.; Frenz, J.; Belenkii, A.; Karger, B. \& Hancock, W. (1993). Ultrasensitive plasmid mapping by high performance capillary electrophoresis. Electroforesis, Vol 14, No. 56, pp. 509-514.

Meacle, F.; Lander, R.; Shamlou, A. \& Titchener, P. (2004). Impact of Engineering flow conditions on pDNA yield and purity in chemical cell lysis operations. Biotechnology and Bioengineering, Vol87, No. 3, pp. 293-302.

Middaugh, C.; Evans, R.; Montgomery, D. \& Casimiro, D. (1998). Analysis of pDNA from a pharmaceutical perspective. J Pharm Sci, Vol87, No. 2, pp. 130-146.

O’Kennedy, R.; Ward, J. \& Keshavarz, E. (2003). Effects of fermentation strategy on the characteristic of pDNA production. Biotecnol. Appl. Biochem, Vol37, pp. 83-90.

Phue, J.; Jun, S.; Trinh,L.; \& Shiloach, J. (2008). Modified Escherichia coli B (BL21), a superior producer of pDNA compared with Escherichia coli $\mathrm{K}(\mathrm{DH} 5 \alpha)$. Biotechnology and Bioengineering, Vol 101, No. 4, pp. 831-836.

Pollard, D.; Kirschner, T.; Hunt, G.; Tong. T; Stieber, R. \& Salmon, P. (2007). Scale up of a viscous fungal fermentation: Aplication of scale-up criteria with regime analysis 
and operating boundary conditions. Biotechnology and Bioengineering, Vol 96, No. 2, pp. 307-317.

Powell, K. (2004). DNA vaccines-back in the saddle again?. Nature Biotechnology, Vol22, No. 7, pp. 799-801.

Prather, K.; Sagar, S.; Murphy, J. \& Chartrain, M. (2003). Industrial scale production of pDNA for vaccine and gene therapy: plasmid design, production and purification. Enzyme and Microbial Technology, Vol33, pp. 865-883.

Prazeres, D.; Ferreira, G.; Monteiro, G.; Cooney, Ch. \& Cabral, J. (1999). Large-scale production of pharmaceutical-grade pDNA for gene therapy. TIBTECH, Vol.17, pp. 69-174.

Prazeres, D.; \& Ferreira, G. (2004). Design of flowsheets for the recovery and purification of plasmid for gene therapy and DNA vaccination. Chemical Engineering and Processing, Vol 43, pp.615-630.

Ribeiro, S. (2002). Isolation of pDNA from cell lysates by aqueous two-phase systems. Biotechnol. Bioeng., Vol78, pp. 376-384.

Robinson, H. (2000). DNA vaccines. Clin Microbial Newslett, Vol23, pp. 17-22.

Ruiz, O.; Pérez, M.; Pupo, M.; Limonta, M.; Torres, D.; Martínez, S.; Macias, K.; Diaz, M.; Proenza, Y.; Valdés, J. \& Martínez, E. (2009). High cell density culture to produce pDNA for gene therapy in E. coli. Biopharm International, Vol22, No. 7, pp. 40-45, ISSN 1542-166X.

Schleef, M. (1999). Volume5a: Recombinant Proteins, Monoclonal antibodies and Therapeutic Gene. Biotechnology, pp. 445-469. WILEY-VHC, ISBN 3-527-28315-3.

Schluep, T. \& Cooney, C. (1998) Purification of plasmid by triplex affinity interaction. Nucleic Acids Res, Vol26, No. 19, pp. 4524-4528.

Schmidt, T.; Friehs, K.; Schleef, M.; Voss, C. \& Flaschel, E. (2001). In-process analysis of plasmid copy number for fermentation control. Pacesetter, Vol5, No. 1, pp.4-6.

Schmidt, T. (2003). Method for the isolation of pDNA. USPatent 6,664,,078 B1. Qiagen GimbH, Hilden, DE.

Schorr, J.; Moritz, P.; Seddon, T. \& Schleef, M. (1995). Plasmid DNA for human gene therapy and DNA vaccines. Production and quality assurance. Ann N Y Acad Sci, Vol 772, pp. 271-273.

Smith, G.; Helf, M.; Nesbet, C.; Betita, H.; Meek, J. \& Ferre, F. (1999). Fast and accurate method for quantitating E. coli host-cell DNA contamination in pDNA preparations. Biotechniques, Vol 23, No. 3, pp. 518-522, 524, 526.

Sofer \& Hagel. (1997). Handbook of process chromatography, a guide to optimization, scaleup and validation. (1 ed.) Academic press.

Stadler, J.; Lemmens, R. \& Nyhammar, T. (2004). Plasmid DNA purification. The Journal of Gene Medicine, Vol6.

Vogel, F. \& Sarver, H. (1995). Nucleic acid vaccines. Clin. Microbiol. Rev., Vol8, pp. 406-410.

Wang, Z.; Le, G.; Shi, Y. \& Wegrzyn, G. (2001). Medium design for pDNA production based on stoichiometric model. Process. Biochem, Vol36, pp.1085-1093.

Weis, G.; Garner, M.; Yarmola, E.; Bocek, P. \& Chrambach, A. (1995). A comparison of resolution of DNA fragment between agarose gel and capillary zone electrophoresis in agarose solutions. Electrophoresis, Vol16, No. 8, pp. 1345-1353.

$\mathrm{Xu}, \mathrm{Z}$.; Shen, W.; Chen, H. \& Cen, P. (2005). Effects of medium composition on the production of pDNA vector potentially for human gene therapy. Journal of Zheijang University SCIENCE, Vol6B, No. 5, pp. 396-400, ISSN 1009-3095.

Yakhchali, B.; Karami, A.; Aflski, E. \& Ahmadi, A. (2007). PDNA production for genetic inmunization in Fed-batch fermentation with feed back controls based on dissolved oxygen (DO) ahd pH. Journal of Sciences, Vol 18, No. 2, pp. 129-133, ISSN 1016-1104. 


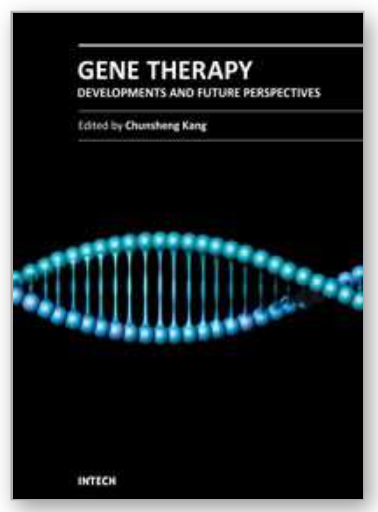

\author{
Gene Therapy - Developments and Future Perspectives \\ Edited by Prof. Chunsheng Kang
}

ISBN 978-953-307-617-1

Hard cover, 356 pages

Publisher InTech

Published online 22, June, 2011

Published in print edition June, 2011

The aim of this book is to cover key aspects of existing problems in the field of development and future perspectives in gene therapy. Contributions consist of basic and translational research, as well as clinical experiences, and they outline functional mechanisms, predictive approaches, patient-related studies and upcoming challenges in this stimulating but also controversial field of gene therapy research. This source will make our doctors become comfortable with the common problems of gene therapy and inspire others to delve a bit more deeply into a topic of interest.

\title{
How to reference
}

In order to correctly reference this scholarly work, feel free to copy and paste the following:

Odalys Ruiz, Miladys Limonta, Jorge Valdés, Martha Pupo and Eduardo Martnez (2011). Scalable Technology to Produce Pharmaceutical Grade Plasmid DNA for Gene Therapy, Gene Therapy - Developments and Future Perspectives, Prof. Chunsheng Kang (Ed.), ISBN: 978-953-307-617-1, InTech, Available from:

http://www.intechopen.com/books/gene-therapy-developments-and-future-perspectives/scalable-technologyto-produce-pharmaceutical-grade-plasmid-dna-for-gene-therapy

\section{INTECH}

open science | open minds

\section{InTech Europe}

University Campus STeP Ri

Slavka Krautzeka 83/A

51000 Rijeka, Croatia

Phone: +385 (51) 770447

Fax: +385 (51) 686166

www.intechopen.com

\section{InTech China}

Unit 405, Office Block, Hotel Equatorial Shanghai

No.65, Yan An Road (West), Shanghai, 200040, China

中国上海市延安西路65号上海国际贵都大饭店办公楼 405 单元

Phone: +86-21-62489820

Fax: $+86-21-62489821$ 
(C) 2011 The Author(s). Licensee IntechOpen. This chapter is distributed under the terms of the Creative Commons Attribution-NonCommercialShareAlike-3.0 License, which permits use, distribution and reproduction for non-commercial purposes, provided the original is properly cited and derivative works building on this content are distributed under the same license. 